\title{
Infant feeding mode predicts the costs of healthcare services in one region of Canada: a data linkage pilot study
}

\author{
Alicia Taylor ${ }^{1}$, Sharmeen Chowdhury ${ }^{1}$, Zhiwei Gao ${ }^{1}$, Hai Van Nguyen², William Midodzi ${ }^{1}$, Nicole Gill³, \\ Beth Halfyard ${ }^{3}$, Leigh Anne Allwood Newhook ${ }^{4}$ and Laurie Twells ${ }^{1,2^{*}}$ (])
}

\begin{abstract}
Objective: The aim is to perform a pilot study evaluating the differences in healthcare service use and its associated costs by infant feeding mode in an infant's first year of life. Data from a prospective cohort study and administrative databases were linked to examine healthcare use in healthy full term infants $(\mathrm{N}=160)$. Exposure was categorized as exclusively breastfed, mixed fed and exclusively formula fed. Outcomes included hospitalizations, emergency room and physician visits. Descriptive statistics and generalized linear modelling were performed.

Results: Overall $\$ 315,235$ was spent on healthcare service use for the sample of infants during their first year of life. When compared to exclusive breastfeeding, mixed feeding and exclusive formula feeding were found to be significant predictors of total healthcare service use costs $(p<0.05)$, driven by costs of hospital admissions. Due to the human and economic burden associated with not breastfeeding, policies and programs that support and encourage breastfeeding should be priority.
\end{abstract}

Keywords: Infant feeding, Breastfeeding, Health Services Research, Healthcare costs, Direct cost, Canada

\section{Introduction}

Human breastmilk is universally acknowledged as the gold standard of infant feeding, as it offers a unique matrix of compounds for optimal growth, health and development in a newborn child [1]. Studies show that breastfeeding reduces the rates of infant morbidity and mortality, as well as decreases the risk of chronic illnesses in childhood [2-6]. The World Health Organization (WHO) and Health Canada recommend mothers exclusively breastfeed their infants to 6 months of age, with continued breastfeeding with complementary foods to 2 years of life and beyond [7, 8]. Research in developed countries has also examined the economic benefit of

\footnotetext{
*Correspondence: Itwells@mun.ca

${ }^{1}$ Faculty of Medicine, Memorial University of Newfoundland, 300 Prince Philip Drive, St. John's, NL A1B 3V6, Canada

Full list of author information is available at the end of the article
}

increasing breastfeeding rates [9-12]. Researchers demonstrated how increasing breastfeeding rates to $90 \%$ of exclusive breastfeeding (EBF) at 6 months has the potential to prevent $\$ 3$ billion in direct medical costs, and $\$ 14.2$ billion premature death costs, annually [9]. In the United Kingdom, researchers estimated that $£ 26.8$ million could be gained annually by avoiding the costs of treating acute infections in infancy and breast cancer in mothers, if EBF rates increased to $65 \%$ at 4 months and $100 \%$ of babies were breastfed at hospital discharge [10]. Similarly, Australian hospital systems estimated costs of \$1-2 million annually for the treatment of common childhood infections due to insufficient breastfeeding [11]. In Canada, little is known about the economic impact of increasing breastfeeding rates, as few studies have examined the impact of infant feeding mode (IFM) on healthcare service use (HSU) [13-16]. Two studies concluded that breastfeeding was strongly protective against infections 
severe enough to require hospital admission; however, both studies were small and focused on Indigenous populations [13-15], and neither study conducted a cost analysis related to HSU. Therefore we sought to conduct a pilot study examining the impact of IFM on HSU costs during an infant's first year of life (YOL) in one region of Canada.

\section{Main text \\ Materials and methods \\ Sample}

Methods from the Feeding infants in Newfoundland and Labrador (FiNaL) study have been previously published [17-19]. In brief, the study was conducted in three phases to evaluate maternal attitudes and infant feeding practices in Newfoundland and Labrador (NL), Canada. Of those who completed phase three of the FiNaL study $(\mathrm{n}=554), 362$ healthy full term infants born in the Eastern Health Region of NL were eligible for the current pilot evaluating HSU. Ineligibility included preterm infants, those unable to breastfeed due to illness (i.e. congenital disorders), multiple births, deceased, or parental refusal. Of this sample, 160 mothers provided their infants health insurance number for the data linkage.

\section{Administrative data}

The series of administrative data was created by the NL Centre for Health Information (NLCHI). Individual level record data were extracted from the Provincial Discharge Abstract Database (PDAD) for hospital admissions, Live Birth System (LBS) for demographics and infant characteristics, MCP Fee-for-Service Physician Claims (FFS) for family doctor and specialist visits, and the MediTech Module (MTER) for emergency room (ER) visits.

\section{Exposure}

IFM was defined using the WHO criteria. 'Exclusive breastfeeding (EBF)' defined infants receiving only breast milk (i.e., expressed or from a wet nurse) and nothing else, except for oral rehydration solution, medicines, vitamins and minerals when needed. 'Mixed feeding' (MF) defined infants receiving breastmilk and other food or liquid including water, non-human milk, and formula. 'Exclusive formula feeding' (EFF) defined infants fed only breastmilk substitutes. Due to the self-reporting of breastfeeding, EBF could only be valid for the first month of life, though information on IFM was collected throughout the first YOL.

\section{Outcomes}

Primary outcomes were HSU and the associated costs for hospital admissions, ER and physician visits. Direct HSU costs reflect those to the payer over a 1 year time horizon.

\section{Statistical analysis}

Deterministic linkage was used to link the FiNaL study and administrative data provided by the NLCHI. Descriptive statistics, either frequencies for categorical variables or means and standard deviations (SD) for continuous variables were conducted. Generalized linear modelling (GLM) was used to compare HSU costs, and maternal and child characteristics between IFM. Billable claims for each healthcare provider visit were summed using the claims provided by the NLCHI. Costs were converted to 2015 Canadian dollars, as all resource intensity weights (RIW) and cost per standard hospital stay (CSHS) used were for the 2015 fiscal year. The average cost of an ER visit for the $\mathrm{EH}$ regional health authority was calculated using the average of the 2014/2015 and 2015/2016 fiscal years. Due to the skewed HSU costs, both base case and robustness GLM analyses were performed. For the base case GLM a gamma distribution and a log link function were used. Following findings from the modified park and box cox tests, the robustness check followed an inverse gaussian distribution and a reciprocal function. A power calculation was conducted for the GLM at an alpha level of 0.05 , by IFM; EBF $(n=107)$, MF $(n=32)$, EFF $(n=21)$. Statistical analysis was conducted using SPSS (IBM 25) software [20].

\section{Results}

There were 160 infant health insurance numbers provided for the data linkage. The recruitment process is illustrated in the Additional file 1. The majority of mothers were Caucasian, 26 years of age or older, partnered, with a household income $>\$ 30,000 \mathrm{CAN}$ and a post-secondary education. Maternal characteristics are outlined in Table 1. Consenting mothers were more likely to be older, partnered, with higher levels of education and household income. All infants were full term (i.e., > 37 weeks gestation), born between 2012 and 2014, with a mean birth weight of $3523.5 \mathrm{~g}$ (SD 455.8). IFM was categorized as $67 \%$ EBF to 1 month, $20 \% \mathrm{MF}$, and $13 \%$ EFF. There were no differences when examining infants gender, and appropriateness of size for gestational age between groups of IFM, $\mathrm{p}>0.05$.

\section{Healthcare service use}

The majority of infants were seen by a family doctor $(n=151)$ within their first YOL, irrespective of feeding mode, and over half $(n=92)$ were seen by a specialist. MF and EFF infants had a higher percentage of specialist visits $(65.6 \%$ and $65.0 \%$, respectively), while $55.8 \%$ of EBF infants visited a specialist during the first year. The highest frequency of billable claims was: no specific illness diagnosed at the visit $(n=591)$, signs 
Table 1 Maternal characteristics (frequency, $\mathbf{n}(\%)$ )

\begin{tabular}{lcccc}
\hline Characteristics & PN1 survey (N=554) & No MCP (N=394) & HSU [admin] (N=160) & P value* \\
\hline Infant feeding mode & & & & \\
$\quad$ EBF at 1 month & $291(52.5 \%)$ & $201(51.0 \%)$ & $107(66.9 \%)$ & $32(20.0 \%)$ \\
$\quad$ Mixed fed & $165(29.8 \%)$ & $116(29.4 \%)$ & $21(13.1 \%)$ & 0.003 \\
EFF & $98(17.7 \%)$ & $77(19.5 \%)$ & $152(95.0 \%)$ & 0.005 \\
Mother's age (> 26 years) & $494(89.2 \%)$ & $344(86.8 \%)$ & $156(97.5 \%)$ & 0.018 \\
Marital status (married/partnered) & $518(93.7 \%)$ & $362(92.1 \%)$ & $156(97.5 \%)$ & 0.003 \\
Education level (post-secondary) & $510(92.1 \%)$ & $354(89.8 \%)$ & $157(98.1 \%)$ & 0.008 \\
Household income (>30,000 CAN\$) & $520(93.9 \%)$ & $363(92.1 \%)$ & $98(61.3 \%)$ & 0.224 \\
Parity (primiparous) & $316(57.2 \%)$ & $218(55.6 \%)$ & $2(1.30 \%)$ & 0.968 \\
Type of delivery (vaginal) & $403(73.0 \%)$ & $286(73.0 \%)$ & $117(73.1 \%)$ & 0.091 \\
Smoking status (current) & $18(3.20 \%)$ & $16(4.1 \%)$ & $151(95.6 \%)$ & 0.0000 \\
Dwelling area (urban) & $253(45.7 \%)$ & $362(94.0 \%)$ & $7(4.4 \%)$ & 0.478 \\
Ethnicity: caucasian & $514(94.5 \%)$ & $23(5.9 \%)$ & \\
Ethnicity: Other (i.e., Asian, Aboriginal, Afro- & $30(5.5 \%)$ & & \\
$\quad$ Canadian) & & & \\
\hline
\end{tabular}

*P value compares those that took part in the HSU study $(n=160)$ to those that did not $(n=394)$

and symptoms not otherwise diagnosed as an infection or disease $(n=225)$, upper respiratory tract infection $(n=92)$, otitis media $(n=61)$, common cold $(n=49)$, disorders of eyes and ears $(n=46)$, thrush $(n=46)$, and atopic dermatitis $(n=37)$. There were 12 infants hospitalized at least once during the first YOL. The length of stay (LOS) ranged from 1 to 7 days. Most commonly, admissions were related to respiratory complications (i.e., upper respiratory tract infection, croup, asthma). EBF infants had fewer hospital admissions $(2.8 \%)$ than that of MF (15.2\%) and EFF (19.0\%), $\mathrm{p}<0.05$. Half of infants $(n=83)$ were brought to the ER at least once during the firstYOL. More MF infants had ER visits (56.3\%) than that of EBF (53.3\%) and EFF infants (38.1\%). MF and EBF infants had significantly more ER visits when compared to EFF infants, $\mathrm{p}<0.01$. Additional information regarding hospital admissions, ER and physician visits can be found in the Additional file 1.

\section{Cost associated}

The direct HSU costs of 160 healthy full term infants during their first YOL amounted to $\$ 315,235.56$ (Table 2). When considering costs associated with HSU post discharge from birth, the expenditures equated to $\$ 127,373.41$. The highest percentage spent on HSU was for hospital admissions, 37.6\%, $(\$ 47,867.56)$, followed by visits to the family doctor, $30.1 \%$, $(\$ 38,271.88)$, emergency room $18.8 \%(\$ 23,805.5)$ and specialists, $13.7 \%$ $(\$ 17,254.3)$ There were no differences between IFM when comparing physician services or ER visits, $\mathrm{p}>0.05$, while EFF infants had higher expenses for hospital admissions than other feeding groups (MF, EBF), $\mathrm{p}=0.010$ (Additional file 1).

\section{Multivariate analysis}

Our sample size provides a power level of $78 \%$ (alpha $0.05)$ to examine the primary outcome of total HSU costs. The base case analysis for the GLM is presented in Table 3. IFM remained a predictor of total HSU costs during an infant's first YOL, after adjustment for residence

Table 2 Total costs associated with each healthcare provider, by infant feeding mode

\begin{tabular}{|c|c|c|c|c|c|}
\hline & Total $(n=156)$ & $E B F(n=104)$ & Mixed $(n=32)$ & Formula $(n=20)$ & P Value \\
\hline Hospitalizations ( $n=159$ ) & $\$ 47,867.56$ & $\$ 5132.90$ & $\$ 24,823.42$ & $\$ 17,911.24$ & 0.141 \\
\hline Hospitalizations ( $n=159)$ (including birth) & $\$ 235,883.92$ & $\$ 128,434.74$ & $\$ 64,126.26$ & $\$ 43,322.92$ & 0.015 \\
\hline Emergency room $(n=160)$ & $\$ 23,805.50$ & $\$ 16,264.60$ & $\$ 4731.52$ & $\$ 2809.34$ & 0.672 \\
\hline Family doctor and specialist $(n=156)$ & $\$ 55,546.18$ & $\$ 36,465.19$ & $\$ 10,949.68$ & $\$ 8131.31$ & 0.972 \\
\hline Total costs & $\$ 127,373.41$ & $\$ 58,345.41$ & $\$ 40,255.41$ & $\$ 28,851.89$ & \\
\hline Total costs (including birth): & $\$ 315,235.56$ & $\$ 181,164.53$ & $\$ 79,807.46$ & $\$ 54,263.57$ & \\
\hline
\end{tabular}

*P value compares all three groups of infant feeding mode 
Table 3 Generalized linear modelling of total healthcare costs during the infant's first year of life

\begin{tabular}{llll}
\hline & \multicolumn{2}{l}{ Base case analysis } & \\
\cline { 2 - 4 } & Coefficient (SE) & $\mathbf{9 5 \%}$ Cl & P value \\
\hline $\begin{array}{llll}\text { Constant } \\
\text { Infant feeding mode }\end{array}$ & $7.408(0.889)$ & $7.234-7.582$ & 0.000 \\
EFF & $0.383(0.118)$ & $0.152-0.615$ & 0.001 \\
MF & $0.408(0.099)$ & $0.212-0.603$ & 0.000 \\
EBF & (Referent) & & \\
Residence & & & \\
Rural area & $0.124(0.090)$ & $-0.52-0.301$ & 0.167 \\
Urban area & (Referent) & & \\
Parity & & & \\
Multiparous & $0.061(0.080)$ & & \\
Primiparous & (Referent) & $-0.096-0.218$ & 0.444 \\
Delivery type & & & \\
Vaginal & $-0.042(0.088)$ & $-0.214-0.130$ & 0.629 \\
Caesarean section & (Referent) & & \\
\hline
\end{tabular}

*EFF, exclusive formula feeding; MF, mixed feeding; EBF, exclusive breastfeeding

(urban/rural), delivery type (vaginal/caesarean section), and parity (primiparous/multiparous). Compared to EBF (to 1 month), both MF and EFF were significant predictors of higher total HSU costs. No other factors were significantly associated with total HSU costs. Based on our robustness check the statistical significance remained, with IFM predictive of total HSU cost.

\section{Discussion}

In the present study, 160 mother-infant dyads were enrolled in a data linkage pilot examining the impact of IFM on total HSU costs. Cumulative HSU cost in the first YOL for all healthy full term infants in one provincial region in Canada was $\$ 315,235.56$, including cost of birth. The highest percentage spent on HSU was for hospital admissions, followed by family doctor, ER and specialist visits. Higher HSU costs were associated with EFF infants when examining hospitalizations (birth and admissions), and significant differences were found between IFM when examining total HSU costs.

Our findings are consistent with the literature, where studies in other countries have shown that infants who had early exposure to formula experienced higher volumes of visits to family doctors, infectious episodes and hospital admissions [21-25]. Similarly, our study found differences when comparing IFM, where EFF infants had higher average spending associated with hospital admissions, family doctor and specialist visits, and both MF and EFF infants were predictive of higher total HSU costs. The WHO recommends EBF for 6 months for full health benefits, and our study demonstrates that differences can be seen between IFM even when EBF to 1 month.

There are a number of strengths of the current study. To our knowledge, this is the first estimate of HSU costs by IFM of a sample of full term healthy infants living in Canada. Our ability to link maternal and child data allowed us to examine the specific characteristics that are associated with higher HSU costs among infant's (i.e., mother's parity, type of delivery and residence), and control for these covariates in our analysis. The advantage of conducting a pilot study has allowed us to assess the feasibility of collecting data in a Canadian context and estimate variability in outcomes to help determine sample size for future larger provincial studies. The administrative database allowed for the calculation of individual level data and the direct costs associated with HSU through the claims of family doctors and specialists.

\section{Conclusions}

In one region of Canada, EFF and MF were found to be significant predictors of the total HSU costs during the first YOL. Further research is needed in a Canadian context examining larger samples, with a necessity for more reliable and valid measures of exposure to capture longer durations of IFM. Due to the human and economic burden associated with no breastfeeding, policies and programs that support and encourage breastfeeding should be a priority for governments and regional health authorities.

\section{Limitations}

Our results are based on a relatively small sample size, where the subsample of the FiNaL Study had a selection bias of primiparous, Caucasian, higher education and household income mothers. We found differences among groups for the total HSU costs, driven mainly by hospitalizations, however significant differences were not observed when examining the costs associated with other HSU (i.e., ER, Physician visits). This could be explained by either having no differences among groups, or that the study was underpowered to examine the differences of ER and physician visits. Due to challenges with collecting exposure data on feeding mode and its duration, our MF and EFF covered the first 6 months of life, but our EBF rate was considered valid and reliable for the first month only. The data on exposure were self-reported by mothers and therefore could result in misclassification. Based on the health insurance claims in NL, the administrative databases can only collect information on FFS physicians. Therefore there are a proportion of family doctors and pediatricians that are salaried that we would not have HSU on, therefore this an underestimate of the use and cost 
experienced in this region. In addition, although we used a health systems perspective to examine the costs, not all costs were included (i.e., medications).

\section{Supplementary information}

Supplementary information accompanies this paper at https://doi. org/10.1186/s13104-020-05228-6.

Additional file 1: Figure S1. Flowchart of participant requirement process. Table S1. Healthcare Provider Visits by Infant Feeding Mode (Frequency, n (\%)). Table S2. Number of Unique Visits to Healthcare Providers and the Associated Costs by IFM (Counts). Table S3. Description of Hospitalizations During The First Year of Life. Table S4. Mean (SD), Median (IQR), Min \& Max of the Total Costs Associated with each Healthcare Provider, By Infant Feeding Mode.

\section{Abbreviations}

BFRWG: Breastfeeding Research Working Group; CMG: Case Mix Group; CSHS: Cost of a standard hospital stay; EBF: Exclusively breastfeeding; EFF: Exclusively formula feeding; ER: Emergency room; FiNaL Study: Feeding infants in Newfoundland and Labrador; GLM: Generalized Linear Modelling; HCP: Healthcare provider; HSU: Healthcare service use; IFM: Infant feeding mode; IQR: Interquartile range; KW: Kruskal-Wallis; LBS: Live birth system; PDAD: Provincial Discharge Abstract Database; FFS: Medical Care Plan Fee-for-Service Physician Claims; MCP: Medical care plan; MF: Mixed feeding; MTER: MediTech Emergency Room; NL: Newfoundland and Labrador; NLCHI: Newfoundland and Labrador Centre for Health Information; NL SUPPORT: Newfoundland and Labrador support for people and patient oriented research trials unit; TPMI: Translational personalised medicine initiative; RIW: Resource intensity weight; SD: Standard deviation; WHO: World Health Organization; YOL: Year of life.

\section{Acknowledgements}

This project is a part of a larger research program aimed at understanding infant nutrition choices in NL and their implications. Dr. Twells and Dr. Allwood- Newhook co-chair the Breastfeeding Research Working Group (BFRWG) under the umbrella of the Baby-Friendly Council of NL. This group is a multidisciplinary team of academic researchers, health professionals (i.e., physicians, nurses, midwives, and pharmacists), students, data linkage specialists, and decision/policymakers. As well as the NL Centre for Health Information for their assistance in providing the administrative data for the analyses, which was funded through the Janeway Foundation. I would also like to acknowledge Louanne Kinsella for collecting data for the HSU subgroup, as well as all of the mothers who took the time to take part in the FiNaL Study.

\section{Authors' contributions}

LT and LAA conceived the study concept. AT was responsible for analysis of data with input from LT, ZG and HVN. AT wrote the initial draft with critical revisions by LT. All authors reviewed the manuscript. All authors were involved in interpretation of the data. Work previously completed on the FiNaL Study was done by SC, WM, BH, NG, LAA and LT. All authors read and approved the final manuscript.

\section{Funding}

The present study was supported by The NL Support Unit TPMI graduate student educational funding, as well as the Janeway Foundation. Both funding bodies played no role in the design, collection, analysis, and interpretation of the data or in writing the manuscript.

\section{Availability of data and materials}

The administrative data that support the findings of this study are available from the Newfoundland and Labrador Centre for Health Information (NLCHI) but restrictions apply to the availability of these data, which were used under license for the current study, and so are not publicly available. Data are however available from the authors upon reasonable request and with permission of the NLCHI. The prospective cohort (FiNaL Study) datasets used and/or analysed during the current study are available from the corresponding author on reasonable request.

\section{Ethics approval and consent to participate}

The study received ethical approval from the Provincial Human Research Ethics Authority (HREA). \# 2017.226. Informed consent was provided by mothers completing surveys in the FiNaL study, consent was provided by providing their infants health insurance number for the data linkage.

\section{Consent for Publication}

Not applicable.

\section{Competing interests}

The authors declare that they have no conflict of interests.

\section{Conflict of interest}

The authors declare that they have no conflicts of interest.

\section{Author details}

${ }^{1}$ Faculty of Medicine, Memorial University of Newfoundland, 300 Prince Philip Drive, St. John's, NL A1B 3V6, Canada. ${ }^{2}$ School of Pharmacy, Memorial University, St. John's, NL, Canada. ${ }^{3}$ Newfoundland and Labrador Centre for Health Information, St. John's, NL, Canada. ${ }^{4}$ Department of Pediatrics, Faculty of Medicine, Memorial University, St. John's, NL, Canada.

Received: 27 May 2020 Accepted: 8 August 2020

Published online: 15 August 2020

\section{References}

1. Pound CM, Unger SL. Canadian Paediatric Society Nutrition and Gastroenterology Committee Hospital Paediatrics Section. Paediatr Child Health. 2012;17(6):317-21.

2. Horta BL, de Mola LC, Victora CG. Long-term consequences of breastfeeding on cholesterol, obesity, systolic blood pressure and type 2 diabetes: a systematic review and meta-analysis. Acta Paediatrica. 2015;104:30-7.

3. Ip S, Chung M, Raman G, Chew P, Magula N, DeVine D, Lau J. Breastfeeding and maternal and infant health outcomes in developed countries. AAP Grand Rounds. 2007;18(2):15-6.

4. Duijts L, Jaddoe VW, Hofman A, Moll HA. Prolonged and exclusive breastfeeding reduces the risk of infectious diseases in infancy. Pediatrics. 2010;126:e18-25

5. Grummer-Strawn LM, Mei Z. Does breastfeeding protect against pediatric overweight? Analysis of longitudinal data from the Centers for Disease Control and Prevention Pediatric Nutrition Surveillance System. Pediatrics. 2004;113:e81-6.

6. Dieterich CM, Felice JP, o'sullivan E, Rasmussen KM. Breastfeeding and health outcomes for the mother-infant dyad. Pediatric Clin North Am. 2013;60(1):31-48.

7. World Health Organization. Exclusive breastfeeding. https://www.who. int/nutrition/topics/exclusive_breastfeeding/en/. Accessed 22 July 2019.

8. Health Canada. Nutrition for healthy term infants: recommendations from Six to 24 Months. 2015. Accessed 22 July 2019. https://www.canada.ca/ en/health-canada/services/canada-food-guide/resources/infant-feeding/ nutrition-healthy-term-infants-recommendations-birth-six-months/6-24months.html.

9. Bartick MC, Schwarz EB, Green BD, Jegier BJ, Reinhold AG, Colaizy TT, Bogen DL, Schaefer AJ, Stuebe AM. Suboptimal breastfeeding in the United States: maternal and pediatric health outcomes and costs. Maternal Child Nutr. 2017;13(1):e12366.

10. Renfrew MJ, McCormick FM, Wade A, Quinn B, Dowswell T. Support for healthy breastfeeding mothers with healthy term babies. Cochrane Database Syst Rev. 2012.

11. Smith JP, Thompson JF, Ellwood DA. Hospital system costs of artificial infant feeding: estimates for the Australian Capital Territory. Aust N Z J Public Health. 2002;26(6):543-51.

12. Victora CG, Bahl R, Barros AJ, Franca GV, Horton S, Krasevec J, Lancet Breastfeeding Series Group. Breastfeeding in the 21st century: epidemiology, mechanisms, and lifelong effect. Lancet (London, England). 2016:387(10017):475-90.

13. Jenkins AL, Gyorkos TW, Joseph L, Culman KN, Ward BJ, Ekeles GS, et al. Risk factors for hospitalization and infection in Canadian Inuit 
infants over the first year of life-a pilot study. Int J Circumpolar Health. 2004;63:61-70.

14. Chalmers B, Levitt C, Heaman M, O'Brien B, Sauve R, Kaczorowski J. Breastfeeding rates and hospital breastfeeding practices in Canada: a national survey of women. Birth. 2009;36:122-32.

15. Mclsaac KE, Moineddin R, Matheson Fl. Breastfeeding as a means to prevent infant morbidity and mortality in Aboriginal Canadians: a population prevented fraction analysis. Can J Public Health. 2015;106(4):e217-22.

16. Costanian C, Macpherson AK, Tamim H. Inadequate prenatal care use and breastfeeding practices in Canada: a national survey of women. BMC Pregnancy Childbirth. 2016;16:1.

17. AlKusayer NM, Midodzi WK, Newhook LA, Burrage L, Gill N, Halfyard B, Twells LK. Psychometric assessment and precision remodeling of the lowa Infant Feeding Attitude Scale to improve clinical use and efficacy among prenatal women in Canada. J Hum Lactation. 2018;34(1):20-9.

18. AlKusayer NM, Midodzi WK, Newhook LA, Gill N, Halfyard B, Twells LK. Determining clinically relevant cutoff scores for the lowa Infant Feeding Attitude Scales among prenatal women in Canada. J Hum Lactation. 2018;34(4):691-8.

19. Newhook JT, Ludlow V, Newhook LA, Bonia K, Goodridge JM, Twells L. Infant-feeding among low-income women: the social context that shapes their perspectives and experiences. CJNR. 2013;45(3):28-49.

20. IBM Corp. Released 2017. IBM SPSS statistics for windows, Version 25.0. Armonk: IBM Corp; 2017.
21. Lamberti LM, Zakarija-Grković I, Walker CL, Theodoratou E, Nair H, Campbell H, Black RE. Breastfeeding for reducing the risk of pneumonia morbidity and mortality in children under two: a systematic literature review and meta-analysis. BMC Public Health. 2013;13(S3):S18.

22. Ladomenou F, Moschandreas J, Kafatos A, Tselentis Y, Galanakis E. Protective effect of exclusive breastfeeding against infections during infancy: a prospective study. Arch Dis Child. 2010;95(12):1004-8.

23. Hanieh S, Ha TT, Simpson JA, Thuy TT, Khuong NC, Thoang DD, Tran TD, Tuan T, Fisher J, Biggs BA. Exclusive breast feeding in early infancy reduces the risk of inpatient admission for diarrhea and suspected pneumonia in rural Vietnam: a prospective cohort study. BMC Public Health. 2015;15(1):1166.

24. Tarrant M, Kwok M, Lam T, Leung G, Schooling M. Breast-feeding and childhood hospitalizations for infections. Epidemiology. 2010;21:847-54.

25. Shiva F, Ghotbi F, Padyab M. Infant feeding and hospitalization during the first six months of life. JPMA. 2007;57(12):599-603.

\section{Publisher's Note}

Springer Nature remains neutral with regard to jurisdictional claims in published maps and institutional affiliations.
Ready to submit your research? Choose BMC and benefit from:

- fast, convenient online submission

- thorough peer review by experienced researchers in your field

- rapid publication on acceptance

- support for research data, including large and complex data types

- gold Open Access which fosters wider collaboration and increased citations

- maximum visibility for your research: over $100 \mathrm{M}$ website views per year

At BMC, research is always in progress.

Learn more biomedcentral.com/submissions 